\title{
Politización, lucha y resistencia en Chile. Una aproximación al caso de la mujer en el Movimiento Juvenil Lautaro (1983-1993)
}

\author{
Politicization, fight and resistance in Chile. An approximation to the case of \\ women in the Lautaro Youth Movement (1983-1993)
}

\author{
Javiera Velásquez Meza \\ Universidad Academia de Humanismo Cristiano \\ javiera.velasquez@usach.cl
}

Fecha de recepción: 9 de febrero de 2018

Fecha de aprobación: 13 de junio de 2018

\begin{abstract}
Resumen
El MAPU-Lautaro puso en el tapete diversas cuestiones ante la dictadura y la izquierda renovada. Una de las que destacó fue el rol que asumió la mujer en las filas lautarinas, siendo un rol criminalizado por la prensa y opinión pública con todo lo que significó ser mujer en dictadura y en la entrante democracia. Profundizamos el rol de la mujer en el Lautaro, con todas las peculiaridades que este conllevó per se, y destacamos algunas características de la militancia femenina, desde los procesos de politización, pasando por el desarrollo político-militar, hasta las acciones de lucha y resistencia de las mujeres en la persecución, encarcelamiento y desarticulación del Lautaro. Así mismo, observamos la mirada de la militancia femenina de una de las organizaciones al parecer más idóneas para la consideración política de la mujer, fuera de la institucionalidad gubernamental.
\end{abstract}

Palabras clave: Movimiento Juvenil Lautaro, Mujer militante, Lucha armada, Prisión política.

\begin{abstract}
The MAPU-Lautaro put on the table several issues before the dictatorship and the renewed left; one of the highlights was the role that women assumed in the lautarine ranks, being a criminalized role by the press and public opinion with everything that meant be a woman in dictatorship and in the coming democracy. We deepened the role of women in the Lautaro, with all the peculiarities that this entailed per se and highlighted some characteristics of female militancy, from the processes of politicization, going through political-military development, to the actions of fight and resistance of women in the persecution, imprisonment and disarticulation of the Lautaro. We also observe the look of feminine militancy of one of the organizations that seems to be the most suitable for the political consideration of women, outside the governmental institutions.
\end{abstract}

Keywords: Lautaro Youth Movement, Militant woman, armed fight, Political prison. 


\section{Introducción}

Historiográficamente, el MAPU-Lautaro, nacido en dictadura y extendido hasta los primeros años de la transición chilena, ha sido uno de los grupos de izquierda armada que aún no posee una amplia gama de trabajos en torno a sí; de hecho, "es el que cuenta con menos investigaciones disciplinarias", ${ }^{1}$ y en comparación a sus símiles, como el Movimiento de Izquierda Revolucionaria (MIR) o el Frente Patriótico Manuel Rodríguez (FPMR), el Lautaro está en mora en lo que respecta a producción académica. Si además incorporamos a la mujer, podríamos señalar que la lista se reduce aún más, estableciendo como una categoría de análisis la perspectiva del género dentro de la lucha armada. Al intentar buscar respuestas teóricas para esto, consideramos que la resistencia armada, en general, se ha visto inserta en un totalizador masculino, donde prevalecen concepciones estereotípicas de género según las cuales los hombres tienden a la violencia, la agresión y hacer la guerra, mientras se asume que las mujeres son pacíficas por naturaleza, apolíticas y víctimas de la guerra. Estos estereotipos de género refuerzan la idea de que la lucha armada y los contextos militarizados son ámbitos de connotación masculina, sin indagarlos críticamente. ${ }^{2}$

El rechazo que generó el Lautaro, -tanto en la izquierda socialdemócrata como en la derecha- puede dar luces también de la falta de profundización en la producción intelectual. En entrevista realizada por Eyleen Faure, Pablo habría señalado que "había un estigma muy grande sobre Lautaro... de toda la izquierda... por ejemplo al Lautaro le adecúa mucho una comparación... el Lautaro fue en los '90 como la VOP en los '70... le incomodaba a todo el mundo...". ${ }^{3}$ Esta peculiar analogía aplica al Lautaro: el rechazo desde la izquierda y el desdén de la derecha, junto con la despolitización y criminalización emanadas de ambos lados, incidieron en que la nueva criatura lograra calar y asentarse en las bases populares organizadas y en resistencia, en tanto las mismas, desencantadas de la política tradicional, buscaban una forma de canalizar la lucha contra la dictadura. Nos encontramos frente a cómo profundizar el rol de la mujer en el Lautaro y comprender su presencia en este, rescatando de la memoria la experiencia militante femenina. Creemos pertinente destacar cuáles fueron las características de la mujer lautarina que le otorgaron un protagonismo propio y no al alero

1 Igor Goicovic, "Temas y debates en la historia de la violencia política en Chile," Revista Contenciosa 3, no. 2 (2014): 14.

2 Luisa Dietrich, "La 'compañera política': mujeres militantes y espacios de 'agencia' en insurgencias latinoamericanas," Colombia Internacional 80, no. 1 (2014): 85.

3 Eyleen Fauré, "Los locos del poder. Aproximación histórica a la experiencia del Movimiento Juvenil Lautaro. (1982-1997)". (Tesis de licenciatura, Universidad de Chile, 2006), 32. La Vanguardia Organizada del Pueblo (VOP) fue una de las organizaciones que más perturbó a la izquierda chilena durante los años previos al gobierno de la Unidad Popular, realizando acciones de sabotaje y boicot entre 1969 y 1971. Desbaratada durante el mandato de Salvador Allende, una de sus acciones más recordadas es el ajusticiamiento de Edmundo Pérez Zujovic el 8 de junio de 1971. 
del hombre, para lo que desarrollamos una aproximación abordada desde tres puntos: los procesos de politización a través de los cuales las jóvenes llegaron a las brigadas del Movimiento Juvenil Lautaro (MJL), el desarrollo político-militar y la experiencia carcelaria. Nos planteamos como objetivo conocer y analizar las características de la militancia femenina lautarina, señalar los factores que incidieron en la decisión de lucha de las lautarinas, identificar procesos que profundizaron su postura radical y establecer las condiciones en que se presentaron estos factores como principal característica de la resistencia femenina y militante durante el ocaso del Lautaro, validando el rol activo de la mujer dentro del combate a la dictadura y la transición. A través de los testimonios de tres ex lautarinas, analizaremos la experiencia de cada una de ellas y nos aproximaremos a la vivencia de ser mujer en la resistencia armada en Chile; intentaremos comprender el proceso social vivido en la época, e identificaremos los distintos orígenes de tres jóvenes que confluyeron en el Lautaro, cuyas distintas etapas de vida en la lucha contra la dictadura, dan cuenta de la activa participación de la mujer como protagonista de la historia. A través de estos tres ítems, recorreremos las vivencias de las tres ex militantes, mostrando con ello los procesos de politización, su entorno familiar, las relaciones políticas e interpersonales en el Lautaro y posteriormente , su experiencia carcelaria que daría lugar a diversas muestras de solidaridad de género.

Cabe señalar que, a través de las entrevistas realizadas, ex militantes dan cuenta de haber conocido su orgánica como MAPU-Lautaro o haber ingresado al Partido MAPU. En función de tal situación, creemos prudente destacar que, si bien nos referiremos al MAPU-Lautaro, destacamos también el Lautaro a secas, más allá del también MJL. Esta dinámica se da en tanto el origen desde el Partido MAPU y los distintos niveles de autonomía alcanzados por las brigadas del MJL, fueron imbricando a la nueva criatura que significó el MJL con las directrices políticas del MAPU. Más tarde, con el surgimiento en 1987 de las Fuerzas Rebeldes y Populares Lautaro (FRPL), ya se hablaría del Complejo Partidario, todos bajo la significancia del Lautaro. Dicho esto, resulta necesario realizar ciertas contextualizaciones previas al presente estudio, focalizado en la militancia femenina del Lautaro, cuyo origen solo puede ser comprendido si nos desplazamos al fin de la década de 1960 e inicios del gobierno de la Unidad Popular, cuando el debate en torno a la lucha armada que tomó lugar dentro de los partidos de izquierda en Chile, contribuyó a la división de algunos partidos políticos. Tal fue el caso del Movimiento de Acción Popular Unitaria (MAPU), cuyo nacimiento en 1969, desde un grupo de jóvenes más radicales y escindidos de la Democracia Cristiana (DC), daba luces sobre el devenir del partido. En mayo de 1972, tras la muerte de Rodrigo Ambrosio, uno de los fundadores del MAPU, las contiendas al interior del partido dejaron observar dos sectores en conflicto, un grupo moderado y otro que optaba por la vía revolucionaria: el MAPU Obrero Campesino (MAPU-OC) y el MAPU “Garretón”, con Jaime Gazmuri y Oscar Guillermo Garretón a sus cabe- 
zas, respectivamente. Con este escenario llegó el 11 de septiembre de 1973, día en que comenzó para la sociedad chilena un nuevo régimen, impuesto bajo la violencia política estatal, el aval de las Fuerzas Armadas y la colaboración de cientos de actores civiles. Durante los restantes años de la década de 1970, partidos proscritos comenzaron una revisión de su teoría y praxis en tanto el golpe militar significaba la derrota del proyecto socialista encabezado por Salvador Allende.

La década de 1980 dio lugar a conocidos debates: ¿radicalización o conciliación?, además de haber dado espacio a los actores políticos, esta vez de manera clandestina, en las bases de los sectores populares, incidiendo en una primigenia politización de aquellos que más tarde salieron a las calles. Sumido en el debate, el MAPU Garretón presenció dos sectores en su interior: aquellos que decidieron ir por un camino más pasivo e institucionalista, aliándose a la Convergencia Socialista (CS), y quienes decidieron tomar la vía revolucionaria desde el sector de Garretón, bandos entre los cuales la crisis definitiva en 1982 significó el nacimiento del MJL.

Con el nuevo actor inserto en las bases territoriales populares, principalmente en sectores periféricos de Santiago, la organización del MJL se estructuró a través de brigadas con direccionamiento político de militantes del MAPU, expandiéndose después a otro de sus frentes, que incluso llegaría a ser uno de los más importantes. Ya en los primeros momentos de las brigadas lautarinas, la presencia de mujeres se hizo notar, siendo el espacio estudiantil secundario uno de los espacios más importantes para la incorporación de estas. Pero ¿cuál fue el camino que estas jóvenes recorrieron hasta llegar al Lautaro? A continuación, observaremos aquellos antecedentes e hitos que significaron la toma de posición política en nuestras entrevistadas, entendiendo aquellos momentos importantes como los detonantes de la chispa revolucionaria que más tarde daría fruto en el combate a la dictadura y el sistema impuesto por esta.

\section{De infancia y juventud: antecedentes de politización}

A través de la historia, el rol de la mujer se ha visto supeditado a la impuesta sociedad patriarcal y al parecer, la academia es uno de los espacios donde más ha calado el sesgo machista. Sin embargo, los trabajos que han puesto en tensión esta postura han ido en alza, al mismo tiempo que los estudios de género han tomado lugar en la palestra de la producción intelectual. Incorporar los roles de la mujer dentro de la política y la lucha armada, resquebraja aún más los cánones establecidos y en este sentido, consideramos necesario el trabajo sobre la mujer militante en una organización que ya cuenta con una escasa cantidad de investigaciones en torno a sí. En cuanto a ciertas consideraciones teóricas, comprenderemos género como un "elemento constitutivo de las relaciones sociales basadas en las diferencias que distinguen los sexos y como 
una forma primaria de relaciones significantes de poder"4; así mismo, como "el campo primario dentro del cual o por medio del cual se articula el poder"s. Aunque no es nuestra intención establecer cuestionamientos epistemológicos específicos sobre el poder, efectivamente es una de las maneras en que se puede observar la subordinación de la mujer, aun cuando en distintas ocasiones este se manifiesta de manera implícita. Así, dicha conceptualización se presenta acorde a nuestros propósitos, en tanto observaremos las relaciones establecidas entre mujeres y hombres del Lautaro, así como también la incidencia de estas en la cotidianeidad de una organización política de izquierda. A propósito, Julieta Kirkwood destaca que:

La discriminación femenina aparecerá disfrazada, postergada como secundaria o, en ocasiones, directamente negada. En parte porque dentro de la gama de relaciones de dominación, la de mayor elaboración teórica es la que se ocupa de las relaciones entre clases antagónicas, y la mujer aparecía, inobjetablemente, repartida en clases sociales. En parte, también, porque las propias mujeres no siempre se visualizaron a sí mismas como objetos de una discriminación especifica, no postulándose, por lo tanto, como sujetos reivindicando su propia opresión sino aceptando, bien o mal, la idea cultural predominante sobre lo femenino como contradicción secundaria. ${ }^{6}$

El contexto en que surgió el Lautaro y los motivos con que se dispuso su ofensiva y resistencia contra la dictadura se plasmaron como lo urgente, es decir, acabar con la dictadura; aun cuando sin perjuicio de esto, la extensión de la lucha armada tras la salida de Augusto Pinochet del poder, diera cabida a otras agendas que planteaban, en palabras simples, la lucha contra el sistema imperante, incluyendo en esto la lucha por la liberación de la mujer y del estereotipado rol social asignado. Sobre las problemáticas femeninas, Kirkwood señala que "Las mujeres mismas desde la izquierda tampoco lo admiten: ya se han integrado a protestar por cambios en la sociedad en su conjunto y no hablan más de "problemas femeninos'." Observar el caso del Lautaro como un grupo de izquierda armada que más se podría preciar de haber incorporado a la mujer en primera línea de combate, nos permite también complejizar este escenario, en tanto las relaciones al interior de la organización se presentan tan significativas de la historia lautarina y de las propias mujeres que combatieron a la dictadura, siendo parte importante del proceso social vivido entre dictadura y transición en Chile. Aun así, se pueden observar ciertos micromachismos, de manera tácita o bien bastante ex-

4 Joan Scott, "El género: una categoría útil para el análisis histórico," en Historia y género: las mujeres en la Europa moderna y contemporánea, ed. Mary Nash y James Amelang. (Valencia, España: Ed. Alfons el Magnánim, 1990), 23.

$5 \quad$ Scott, "El género...," 26.

6 Julieta Kirkwood, Ser política en Chile. Las feministas y los partidos (Santiago: Ed. FLACSO, 1986), 49.

$7 \quad$ Kirkwood, Ser política en Chile, 58. 
plícita, los que entenderemos como:

Actitudes de dominación "suave" o de "bajísima intensidad", formas y modos larvados y negados de abuso e imposición en la vida cotidiana (...) Muchos de estos comportamientos no suponen intencionalidad, mala voluntad ni planificación deliberada, sino que son dispositivos mentales y corporales incorporados y automatizados en el proceso de "hacerse hombres", como hábitos de funcionamiento frente a las mujeres. ${ }^{8}$

Las relaciones establecidas entre mujeres y hombres lautarinos se vieron cruzadas por diversas actitudes que, a propósito o accidentalmente, fueron invisibilizadas en virtud de las medidas y preocupaciones más inmediatas del contexto, como significaban terminar con la dictadura y extender la guerra por el Chile Popular. Pero, ¿no se caracterizó el Lautaro y sus políticas revolucionarias por incorporar otras reivindicaciones, que la izquierda tradicional no había tomado hasta entonces?, ¿cómo fue vista esta experiencia desde las lautarinas? Sin la intención de establecernos como la verdad o la historia oficial, en este primer apartado, encontraremos los orígenes de aquella más prístina politización a la luz de un país sometido al terrorismo de Estado y los horrores de la dictadura. A su vez, indagaremos cómo las mujeres fueron tomando su propio espacio para convertirse en protagonistas de un oscuro episodio de la historia reciente en Chile y ser partícipes de un cambio social de carácter revolucionario.

\section{Resistencia en Chile bajo régimen. Contexto general}

Tras el golpe de Estado del 11 de septiembre de 1973, la dictadura cívico-militar que se impuso en Chile, el reordenamiento social forzado y los crímenes entonces efectuados, fueron forjando en buena parte, el malestar que llevó a la sociedad chilena a superar el miedo al régimen. Hacia 1980, un peculiar plebiscito legitimaba la dictadura a través de la Constitución Política que, entre muchos puntos, pretendía limitar la política a las autoridades y neutralizar la politización del pueblo chileno. Otro de los puntos más importantes en torno a los cambios implantados en Chile, fueron las reformas económicas neoliberales que llevaron consigo los denominados Chicago Boys, un grupo de economistas pertenecientes a una conservadora universidad chilena y que se especializaron en la política neoliberal de la Universidad de Chicago, para ser más tarde artífices y partícipes de los cambios estructurales que se vivirían en el país. Sin embargo, lejos de impulsar y hacer crecer la economía chilena, las reformas solo significaron en la práctica una acrecentada brecha entre ricos y pobres que marcó la desigualdad social, esta última garantizada por la dictadura como medio para asegurar su posteridad. Así, en 1982 una importante crisis económica dejaba a cientos de chilenos cesantes e inestables monetariamente; quienes pudieron emigraron a otros

Luis Bonino, “Los Micromachismos," Revista La Cibeles (2004). 
países, mientras otros tantos se quedaron a sobrevivir en Chile, bajo las condiciones que conllevaba la dictadura. Diez años después del golpe de Estado, el hastío se volcó a las calles un 11 de mayo de 1983, con el primer llamado a paro nacional, que si bien fue convocado por la Confederación de Trabajadores del Cobre (CTC), contó con el respaldo de diversos sectores sociales. La jornada de protesta fue altamente activa como también reprimida, siendo el puntapié inicial de la escalada del rechazo al régimen que salió a marchar constantemente; además, fue el incentivo principal para la organización de la izquierda armada. Tampoco es desconocido para la historia reciente en Chile la importancia que adquirieron las mujeres en la protesta contra la dictadura de Pinochet, despojándose de roles pasivos para ser protagonistas de la historia. Organizaciones de estudiantes, trabajadoras, mujeres por los derechos humanos, entre otras, salieron del rol asignado durante años al alero del hombre y como pilar fundamental del hogar y la familia convencional, para entregarse a distintos caminos de lucha. En este escenario de agitación social nació el MJL, creciendo paulatinamente como una opción para la juventud de oposición que además se posicionó como una orgánica fuera de los preceptos tradicionales de la vieja izquierda chilena, dando un lugar a la mujer, quizás sin darse cuenta de las implicancias históricas que se estaban llevando a cabo.

\section{Buscando la lucha. ¿Comunistas, socialistas o lautaristas?}

Comprendiendo el contexto en que se desenvolvió la sociedad chilena en la década de 1980, no parece fortuito que gran parte de la juventud quisiera luchar contra el régimen. En ese sentido, distintas experiencias previas influyeron sobre el ingreso al Lautaro de nuestras entrevistadas. Pero este paso no podría haber sido dado sin el factor familiar, donde lo más cotidiano significó la toma de conciencia sobre algo que estaba ocurriendo y que "algo había que hacer". Las vivencias desde el contexto familiar, como un primer espacio de relaciones sociales, fueron para muchas lautarinas, antecedentes claves en cada uno de sus procesos de politización, donde el despertar social e individual se manifestó en el momento y lugar adecuados. Una entrevistada recuerda:

Yo vivía cerca del Estadio Nacional y el ruido de los helicópteros me quedó súper marcado (...) a los doce años me fui a Francia... y ahí se me abre el mundo porque allá todo el mundo habla de la dictadura de Pinochet, de apoyar a Chile, de la solidaridad y de a poco empiezo a descubrir que algo pasaba en mi país, que no entendía mayormente... ${ }^{9}$

Por otra parte, en las movilizaciones que se comenzaron a realizar contra la dictadura, la masiva participación social fue decisiva para muchas personas que no se

9 Entrevista personal, Claudia, ex lautarista, diciembre 7, 2016. 
vieron afectadas directamente por el terrorismo de Estado, en torno a los crímenes y la desfragmentación de la izquierda parlamentaria y la izquierda armada; no obstante, estos sí sufrieron los embates de la dictadura, y optaron por actuar de forma efectiva contra el régimen. El historiador Mario Garcés y el sociólogo Gonzalo de la Maza, señalan que "mediante diversas formas de lucha predominantemente civiles, la protesta fue también relevante por su capacidad para articular a actores sociales y políticos diversos en el plano de la acción concreta contra el régimen"10. Bajo este contexto, una ex lautarina señala que su familia:

Era de izquierda, mi papá era socialista, pero era obrero, mis hermanas son mayores que yo, entonces en mi familia mis hermanas vivieron la Unidad Popular siendo jóvenes, y yo sentía al menos en mi familia en la dictadura, que se había perdido algo muy fuerte. Entonces me crie en esa lógica... siempre sentí eso en mi casa, esa sensación que estábamos viviendo algo terrible. Y cuando empezó la época de las protestas yo empecé a ir chica con mis papás. ${ }^{11}$

A su vez, Andrea relata:

En mi familia no había experiencia militante directa, al contrario, en mi casa se vivía con mucho susto a tener discos de Quilapayún o libros de izquierda (...) como a los 12 (años) empecé a... como que uno crece con la idea de que los milicos son malos (...) y a partir de todos los discursos antimarxistas de Pinochet, aparece súper atractivo investigar de qué se trata aquello que él demoniza tanto: el marxismo, el comunismo. ${ }^{12}$

Podemos apreciar sobre este testimonio una dinámica peculiar y paradójica que se pudo repetir en más de algún caso en la sociedad chilena: el interés que desencadenó la prohibición reiterativa y tajante del marxismo en Chile por parte de la dictadura, influyó en la decisión de Andrea de inmiscuirse en la activa oposición al régimen, por cierto, amparada de manera implícita de diversas maneras por el contexto familiar. Sobre esto, Gerardo Necoechea señala la existencia de tres vías de politización. Una que tendría directa relación con los entornos familiares, ya sea durante la infancia o adolescencia del individuo, una segunda vía que diría relación con la propia experiencia vivida, y una tercera a través de la reconstrucción de las ideas en función también de la experiencia. Podemos comprender la importancia del legado familiar en tanto se muestra como primer vínculo con el acontecer político y social de Chile en la época, así como también la relevancia que va adquiriendo la experiencia personal en la formación de cada lautarina. En tal sentido, la relevancia y coherencia de los hitos

10 Mario Garcés y Gonzalo De la Maza, La explosión de las mayorías. Protesta nacional 1983-1984 (Santiago de Chile: Editorial ECO, 1985), 18.

11 Entrevista personal, Mujer ex lautarista, septiembre 20, 2017.

12 Entrevista personal, Andrea, ex lautarista, noviembre 30, 2016. 
formadores de conciencia política cobran sentido, estableciendo que una de estas vías de politización se presenta "como revelación repentina que marca un antes y después en la vida." ${ }^{13}$ Creemos que estos son puntos claves en los procesos de politización de las lautarinas, en tanto, tras la herencia familiar, se abrieron paso en las historias personales las primeras experiencias de militancia política y que, enmarcado durante la década de 1980, tiene significancia también en tanto las mujeres comenzaban a salir a las calles (en primera fila), siendo parte de un importante proceso histórico. En esa dirección, una ex lautarina que inició su camino de militancia política en la Juventud Socialista (JS) relata:

Vino toda la efervescencia secundaria y milité en la JS, bien chica y había una lógica ahí como de formación (...) hubo un verano que me tuve que quedar sola en Santiago y todo el mundo andaba en trabajos voluntarios y se suponía que me iban a contactar y no me contactaron (...) entonces a raíz de esa irresponsabilidad de esta gente con la que me tenía que juntar me apesté con la JS y justo ese verano una amiga mía sí había ido a los trabajos voluntarios y había conocido al Lautaro... me llevó unos documentos (...) y a mí me encantó el Lautaro, como "jesto es lo que yo quiero!” (...) el tema de las recuperaciones, de ir a la acción más directa -que en esa época no la mencionábamos así- pero pa' mí era lo mejor del Lautaro, porque yo tenía ganas de hacer cosas, no quería pasarme en asambleas discutiendo, yo sentía que era un momento álgido, por eso entré al Lautaro. ${ }^{14}$

En este caso, la irresponsabilidad asociada por la entrevistada a la JS habría actuado como detonante del desencanto respecto a partidos convencionales, y adquirió significancia en cuanto fue el paso previo que posibilitó el ingreso de la joven al Lautaro, esta vez, a través del tejido social establecido por sí misma, aún a una edad bastante corta. En similar línea, Andrea recuerda:

A los 13, 14 años conocí gente de las Juventudes Comunistas y empecé a militar ahí, a leer más, en el '85 (...) en esa época mi lectura era que era una organización un poco instrumental con la gente, la idea de un discurso que se dice a las masas pero otro el que se hace; la gente del Frente me complicaba porque lo entendía como súper necesario pero al mismo tiempo se quería disfrazar, la idea de un Frente que tenía sentido sólo en la medida en que terminaba con la dictadura y a esas alturas yo ya había entendido que el problema iba más allá de la dictadura... el problema no se resolvía con que la gente pudiera votar, había un problema estructural mayor y en ese discurso... medio hipócrita del PC (Partido Comunista) llegué al Lautaro. ${ }^{15}$

13 Gerardo Necoechea, "El proceso de politización desde una perspectiva de historia oral: militantes de izquierda latinoamericanos, 1960-1990," Revista Tempos Históricos 17 (2013): 166.

14 Entrevista personal, Mujer ex lautarista, diciembre 9, 2016.

15 Entrevista personal, Andrea, noviembre 30, 2016. 
Por su parte, bajo su estadía en Francia, Claudia generó vínculos con otros grupos, principalmente con el MIR en el exilio y sus grupos de apoyo, lo que también generó una militancia previa al ingreso al Lautaro, aún en un complejo escenario político interno de tal orgánica. Tal como fue la tónica en los anteriores casos que hemos visto, precedida de determinadas experiencias de vida que se fueron plasmando en la identidad que fue forjando la joven Claudia y, tras haber retornado a Chile, ella comenta:

Entro al liceo acá y empiezo a hablar con algunos compañeros que me empiezan a contar cómo se organizan pero con ningún vínculo... empiezo a conversar con gente cercana al MIR y les cuento que había estado en París, empiezo a encontrar el hilito y llego a la Juventud Rebelde Miguel Enríquez (JRME) y milité con ellos (...) pero era el período que el MIR entró en crisis, así que mi militancia se vio bastante afectada... nos juntábamos mucho a leer y estudiar; poca acción y yo siempre decía "ya, pero falta un poquito de acción porque hay que hacer cosas" (...) y tenía este grupo de amigos que eran del liceo donde había gente del Lautaro... y yo sola los busqué a ellos y les dije "me encanta el MIR, pero está en crisis, no estamos haciendo nada, nos la llevamos en reuniones, leyendo...", harta formación política, pero aterrizando en la realidad y coyuntura del momento de hacer acciones, insertarnos en el medio estudiantil que nos tocaba en ese momento, muy poco... y sentía que eso era súper necesario y ahí les pedí militar con ellos, entrar al Lautaro. ${ }^{16}$

A partir de esto, es posible también reconocer tres momentos del MIR, del Partido Comunista y del Partido Socialista en la resistencia chilena, que dan cuenta del interés político de las jóvenes, de las ganas de actuar y luchar contra la dictadura. No sobra agregar que, aun así, estas se vieron afectadas en tanto los partidos políticos convencionales, estando inmersos en la propia normatividad burocrática de la institución gubernamental y la necesidad de actuar bajo los parámetros establecidos, alejaron cada vez más la política partidista de los sectores populares que se quedaron en el país y protestaron contra el régimen, hasta su salida. La inserción de las jóvenes secundarias en sus espacios correspondientes también se condice con su pronta salida de los espacios como MIR, PS o PC, en tanto el Lautaro abarcaba diversos puntos que en los preceptos de la vieja izquierda chilena no tenían espacio, como simplemente la importancia de la felicidad en la vida de cada militante, despojada por causa de los clásicos martirologios.

Los relatos presentados hasta ahora tienen coherencia en tanto las primeras relaciones sociales establecidas y las experiencias políticas previas al ingreso al Lautaro, se complementan en las que Necoechea ha descrito como vías de politización. Dichos procesos en las jóvenes lautarinas, se fueron complejizando hasta llegar a una política

\footnotetext{
16 Entrevista personal, Claudia, octubre 13, 2017.
} 
radical, en línea con lo establecido por la organización. El mismo autor ha señalado que, "los individuos llegan a la política no sólo por su voluntad sino por el entramado social en el que se hallan insertos" ${ }^{\prime 17}$. Para este caso, el contexto álgido de despertar que vivía la sociedad chilena en el momento que estamos analizando, alimentaba y empujaba esas ganas de actuar contra las injusticias que se hacían cotidianas y se naturalizaban involuntariamente quizás. Ya en las filas del MJL, las lautarinas comenzaron su lucha más definitiva contra el régimen y el modelo impuesto por la dictadura, que significó también la extensión de la guerra con posterioridad a la llegada de la democracia pactada; tras haber recorrido diversas experiencias y otorgado vida a las ganas de hacer algo por cambiar las cosas, ¿de qué manera influirían estas experiencias en el Lautaro? Desmarcándose de sus militancias previas, los posicionamientos políticos de cada lautarina entraron en conflicto y crítica a las orgánicas en donde se desenvolvieran, antes de llegar al MJL. El avance y crecimiento del Lautaro, así como la radicalización en teoría y práctica tuvo lugar de manera directamente proporcional entre la mayoría de sus militantes, quienes por opción y decisión accedieron a "vivir y hacer la revolución”. En el siguiente apartado, nos aproximaremos a poder conocer cómo se vivió y de qué manera se observó la experiencia de ser mujer en la izquierda armada.

\section{Desarrollo político y accionar militar}

En las brigadas lautarinas, las jóvenes comenzaron un camino de reafirmación revolucionaria, aspirando además a construir el socialismo tras la victoria sobre la dictadura y la instauración del Chile Popular a través de la Guerra Insurreccional, estrategia del Lautaro que cimentó sus bases desde 1985 y que se refrendó en 1988 con la declaración de la Guerra Insurreccional de Masas (GIM) durante el Tercer Congreso llevado a cabo el verano del mismo año, donde el poder de fuego hizo más evidente la radicalización en alza de la organización. El crecimiento paulatino de las brigadas del MJL fue fundamental en las políticas y prácticas llevadas a cabo tanto por mujeres como por hombres decididos a luchar contra el sistema impuesto por la dictadura y en tal sentido -de acuerdo a diversos testimonios de ex lautaristas-, los secundarios jugaron un rol primordial en las filas del Lautaro. Mujeres secundarias que se despojaron de la pasividad asignada a ellas, y que decidieron entrar en la acción, ¿cuál fue el alcance de esta presencia en la organización? En este segundo apartado, observaremos el accionar de las mujeres como militantes políticas y las relaciones entre mujeres y hombres establecidas dentro del MJL.

$17 \quad$ Necoechea, "El proceso de politización...," 163. 


\section{1 “La brigada de las minas”. Secundarias lautarinas}

Aún con un alto trabajo político en las poblaciones periféricas de Santiago, el frente secundario siguió tomando relevancia, estableciéndose como uno de los espacios que más militantes daría al Lautaro, probablemente por el hecho de estar inserto en un espacio que propició más el debate teórico y altamente politizado, incluso "sobreideologizado" como algunos entrevistados recuerdan. Con todo y al parecer aún relegado, el frente estudiantil fue un importante estímulo para las jóvenes brigadistas, en tanto, tras el despertar que significaron las jornadas de protesta nacional posteriores a mayo de 1983, la reactivación del movimiento estudiantil fue uno de los principales pilares sobre los cuales se erigió la movilización social contra la dictadura. Bajo este escenario, una ex lautarina recuerda:

Me metí en una brigada secundaria donde habíamos puras mujeres: "la brigada de las minas", así nos decían (...) y éramos un valor, que éramos mujeres y teníamos ese espacio, que éramos secundarias y hacíamos barricadas... iy era casualidad! De repente pasó que habíamos puras mujeres, precisamente en esa brigada (...) éramos ¿ocho? Hay algunas que veo hasta el día de hoy por otras cosas, pero nunca he vuelto a hablar del tema. ${ }^{18}$

Efectivamente, no se propuso de manera política como un acierto en la lucha contra el sistema, ni se proyectó a largo plazo de una determinada manera, pero la brigada de las mujeres fue un punto quizás bastante oculto en la historia del Lautaro y que puede ser uno de los fuertes en torno a las lautarinas y a su incidencia en la orgánica. Nos aventuramos a señalar que el contexto socio-cultural de la época no relevó los temas de género ni mucho menos el feminismo como se exponen actualmente, y por tanto no propició el análisis y la conciencia de lo que estaban significando aquellas prácticas, impidiendo la posibilidad de dar la relevancia que hoy sí habría adquirido. Lo cierto es que, azaroso o no, la brigada de las mujeres llevó a cabo acciones por sí solas, entendidas bajo el contexto en que se desenvolvió dentro del espacio estudiantil secundario, quienes se posicionaron con gran ímpetu frente a la dictadura, a diferencia de otras organizaciones estudiantiles, como las universitarias. Las acciones de la brigada secundaria de mujeres lautarinas se refirieron principalmente a nivel propagandístico, como militantes políticas insertas en el mundo estudiantil, a barricadas, agitación, panfleteos, así como la propia acción directa realizada solo por mujeres. En testimonio de Marcela Rodríguez, ex lautarista que cayó herida en 1990, ella señala:

En una oportunidad hubo una acción en que participó un grupo de 20 mujeres, solamente mujeres. Hizo una recuperación en una farmacia de medicamentos, anticonceptivos y preservativos. Pero no hubo conciencia feminista ni de género. En general, 
todas las cosas se hacían en conjunto. Cada uno aportaba lo suyo. No se podía decir vamos a ser un grupo de mujeres y vamos a ser mejores que los hombres. No. Ser revolucionario es ser todos iguales. ${ }^{19}$

Casi en similar línea, Claudia destaca que, "respecto al rol de la mujer, nunca sentí que... si se organizaba una acción 'no, las chicas van a mirar'. No, la que quería estar en primera fila, estaba." ${ }^{20} \mathrm{Y}$ si bien se destaca el poder actuar siempre en conjunto, mujeres y hombres tanto en la cotidianeidad como en la acción política, creemos que la necesidad de observar la experiencia de ser mujer en un grupo guerrillero, también conlleva la crítica y las complejidades a las cuales se puede enfrentar una mujer en diversos aspectos del diario vivir, tanto ayer como hoy en más de algún caso. Así, existen testimonios que remiten a la dificultad de ser mujer en jefaturas, como hay otras experiencias que lo niegan. Insertas en una brigada donde había solo mujeres, no se observaría tal problema, sin embargo, en otros espacios y estamentos, la situación sería distinta. A propósito, Andrea reflexiona:

Creo que había más complejidad -me tocó vivirlo- con las jefaturas... a mí me pasó, lo que un compañero decía en tres palabras, yo tenía que decir quince; ahora eso era mucho más en los secundarios. Los estudiantes a diferencia de lo que uno pudiese pensar, respecto de la gente que militaba en población, eran mucho más machistas. Si era un hombre el que mandaba, ya. Pero ¿una mujer? "A ver, muéstrame que te la puedes y después lo hago". ${ }^{21}$

Cabría cuestionarse si en el momento histórico en que se vivieron estas experiencias, las distinciones negativas fueron consideradas como tales y de ser así, si fueron tomadas en cuenta para el posicionamiento político de organizaciones políticas no convencionales, como fuera el caso del Lautaro; o, por caso contrario, si existieron políticas públicas destinadas a tales condiciones, sobre lo que nos aventuramos casi de manera inmediata a señalar su negativa. Probablemente, podríamos considerar que las políticas de Estado en Chile han incluido como materias, distintas aristas de lo que podríamos señalar como un feminismo burgués, apenas desde 2010. Lo cierto es que, en la práctica, las distintas disposiciones no han sido aceptadas ni validadas por organizaciones feministas que luchan actualmente, por ejemplo, por avanzar en un aborto legal; organizaciones que se asumen como políticas y que han tomado muchos valores que el Lautaro puso en la palestra en su momento, como el derecho y la necesidad de vivir una sexualidad plena, tanto para hombres como también mujeres, el

19 Cherie Zalaquett, Chilenas en armas: testimonios e historia de mujeres militares y guerrilleras subversivas (Santiago: Ed. Catalonia, 2009), 294.

20 Entrevista personal, Claudia, octubre 13, 2017.

21 Entrevista personal, Andrea, noviembre 30, 2016. 
derecho al goce pleno de todas las sensaciones, el derecho a decidir y llevar una maternidad responsable y compartida, el derecho a la igualdad laboral, entre muchos más puntos que han recordado nuestras entrevistadas. Hablamos de tópicos que no serían considerados en una política institucional y garante de un orden conservador. Se hace aquí necesario y significativo destacar que las políticas propugnadas por Lautaro desde un primer momento, dispusieron el rechazo a la farsa electoral en que se convertiría el plebiscito del 5 de octubre de 1988, cuando se presenta el triunfo del No a Pinochet, el cual mostraba a la sociedad el término de la dictadura, al menos en lo formal. Mas la imposición del modelo que trajo la dictadura aún sigue vigente en Chile, viviendo el día a día con bastiones importantes de la herencia pinochetista. Ante esto el Lautaro respondió con la extensión de la lucha hasta los primeros años de la transición pactada en Chile, validándola en tanto la llegada de la democracia no garantizaba el cambio social al que aspiraba el movimiento, el que incluía efectivamente, la liberación femenina. De esta manera, a pesar de la posibilidad de participación tanto de mujeres como hombres a la par, podemos observar algunos casos que dan paso a una crítica que hoy se puede realizar en retrospectiva con un mayor bagaje cultural y teórico en torno a temas como el feminismo. Una de nuestras entrevistadas señala:

En mi reflexión fui una igual, por el nivel de acción y de participación. Pero me acuerdo... un compañero que hizo una pataleta porque me habían pasado un fierro ${ }^{22}$ mejor que a él. Y claro, eso es una expresión del machismo de él (...) pero hace veinticinco años atrás nosotros no teníamos incorporado eso... salvo ese incidente, que lo tengo súper claro y fue como “iay, qué se cree!” y yo que en ese momento no era feminista, no me sentí atacada particularmente por ser mujer, pero claro yo decía, si hubiera sido hombre él no habría dicho eso. Antes no era una categoría de reflexión, con los años lo he visto y podido analizar de otra manera. ${ }^{23}$

Tal punto parece clave para la comprensión de distintos factores que influyeron en el proceso al interior del Lautaro, como ya lo hemos señalado de manera previa y dice relación con las características culturales y sociales de la época, donde efectivamente los asuntos de género no se encontraban en el tapete como hoy en día. Chile, el país de la "democracia cartucha" en la jerga lautarina, estaría muy lejos por entonces de una apertura cultural respecto a ciertos temas particulares como el sexo, las drogas $\mathrm{u}$ otras que tuvieron un lugar en la política lautarina, más restringido aun al hablar estos tópicos en torno a la mujer. Al respecto creemos necesario destacar lo que Marco evoca el siguiente recuerdo:

22 Denominación popular para armas de fuego.

23 Entrevista personal, Mujer ex lautarista, diciembre 9, 2016. 
Las bromas sexistas nunca las cuestionamos... éramos producto de la misma sociedad, avanzábamos en muchas cosas, pero no éramos una organización que tenga las preocupaciones de las organizaciones de hoy. Porque no existían en la sociedad esas preocupaciones. Tampoco éramos iluminados, estábamos en la sociedad. ${ }^{24}$

En el MJL las mujeres tomaron su espacio, sin darse cuenta de lo que aquello estaba significando en las trayectorias de los grupos de izquierda armada en Chile. Pero ¿fue así el desconocimiento, o de todas maneras se vislumbraba un tanto la implicancia histórica de involucrar a la mujer en el combate y sacarla del encasillado rol que le asignó el sistema? Frente a estos cuestionamientos, es preciso señalar que en 1990 Diego Carvajal ${ }^{25}$, Secretario General del Lautaro, destacaba:

Las compañeras han tenido y tienen un rol destacado en nuestra organización y en la realización de nuestra política y que ha sido así entendido y difundido también por la prensa enemiga (...) Esta mezcla de mujer y subversiva, de mujer y revolucionaria, en sociedades como las nuestras golpea vitalmente puntos esenciales de la dominación. El machismo rebalsa en situaciones de este tipo. Son mezclas insoportables y dolorosas para el capitalismo. ${ }^{26}$

Tal como señalaba Carvajal, el choque entre la mujer combativa y la sociedad inserta en el capitalismo, más aún cuando esta se encontraba bajo una dictadura que intentó copar incluso los aspectos más cotidianos de la sociedad chilena y por cierto de la mujer, se hizo más fuerte e impactante ante la opinión pública, incentivada además por la prensa oficial de la época. No es casual que, durante el gobierno de la UP, las mujeres agrupadas de diversos sectores acomodados hayan sido punto clave ante el requerimiento de la derecha por la -según ellos-intervención militar. Al respecto Kirkwood señala:

Precisamente en los años 70-73 será desde los $\operatorname{Cemas}^{27}$ de los barrios altos que surgirá y se multiplicará el Poder Femenino, que da a luz la Marcha de las cacerolas vacías (...) Explícitamente se reconoce que la movilización anticomunista de las mujeres no fue un movimiento destinado a incorporarlas permanentemente en el ámbito de lo político, y que tampoco representaba un feminismo de derecha. Por el contrario, la movilización de las mujeres obedece a requerimientos muy coyunturales de defensa de los valores morales de la patria y la familia. ${ }^{28}$

24 Entrevista personal, Marco, ex lautarista, enero 18, 2016.

25 Nombre político de Guillermo Ossandón.

26 "La Toma de lo cotidiano: entrevista a Diego Carvajal, secretario general del Partido MAPU” Facsímil. Febrero 1990, 14.

27 "Centros de Madres".

28 Kirkwood, Ser política en Chile, 57-58. 
En tal sentido, aquellos sectores y en especial, aquellas mujeres adherentes de la dictadura militar, pretendían instaurar y defender el rol que relegaba a la mujer a la sumisión y en lo práctico, a las tareas domésticas y reuniones sociales coloquiales, pero la irrupción en la resistencia armada no tan solo de las lautarinas, sino también de mujeres rodriguistas y miristas, planteaba un peligro y una distorsión para la moral ciudadana. El actuar de las lautarinas a la par de sus compañeros fue algo que desde los primeros momentos llamó la atención en la opinión pública, especialmente aquella influenciada por los medios de comunicación proclives al régimen, que irrumpieron caricaturizando y despolitizando a las lautarinas bajo la figura de la mujer metralleta.

\subsection{En portada y primera línea de combate: la "mujer metralleta"}

Fue en 1990 cuando un soberbio "acierto fotográfico" del burdo diario de circulación nacional La Cuarta, perteneciente al acomodado y convencional Grupo Copesa, dio vida al mito periodístico de la "mujer metralleta"; una mujer fría, calculadora, de alto mando y a quien todo lautarista obedecía ciegamente era la imagen vendida por la prensa, avalando así el juego institucional que buscaba el desarme de los grupos aún en lucha y consecuentemente, la despolitización de los mismos. Como hemos visto, el no encontrar dentro de las preocupaciones de la época los temas de género, da luces de una sociedad aún muy conservadora, machista y todavía sumisa ante el patriarcado como un modelo, al parecer, inherente al sistema capitalista y bastante naturalizado. En este contexto, es comprensible cuán chocante pudo ser la aparición de una mujer armada en los albores de la democracia, más aún cargada de discursos oficiales y mediáticos que posicionaron a la mujer metralleta como una más de delincuentes y desadaptados que rompían la paz social y no comprendían el momento histórico que vivía el país.

La persecución del gobierno de Aylwin significó la caída paulatina de más de una mujer metralleta, rompiendo así el ideario de la caricatura personificada en una sola mujer. Sin embargo, sería tras el fallido rescate de Marco Ariel Antonioletti desde el Hospital Sótero del Río, el 14 de noviembre de 1990, que una lautarina asumiría tal rol. Marcela Rodríguez, alcanzada por uno de los disparos del tiroteo que le significaron la paraplejia de por vida, fue detenida y trasladada al hospital de la ex penitenciaría, donde fue interrogada por el ministro en visita Jorge Medina Cuevas y a quien habría confirmado ser el renombrado personaje. Sobre la caricatura de la mujer metralleta, Cherie Zalaquett señala:

Fue la punta de lanza de la propaganda armada del Lautaro, con la que acaparaban las portadas de la prensa escrita y de los noticiarios televisivos. El apodo surgió por primera vez en un titular del vespertino La Segunda en 1988 a propósito de violentos 
asaltos bancarios protagonizados por una mujer, aunque no siempre era la misma. ${ }^{29}$

La mujer metralleta se tradujo en la práctica como el simbolismo de la relevancia adquirida por las mujeres dentro de la organización y que, en palabras de Claudia, permitía la acción de las mismas, así como también reconocía el valor que había en ellas, quizás de manera tácita o no explicitada de manera certera para la época determinada en que se desenvolvieron las luchas del Lautaro. El avance de acciones y la llegada a nuevos espacios, permitió el constante desarrollo político militar de las lautarinas, con altos y bajos. Claudia recuerda:

Hicimos acciones de propaganda armada en el peda, ${ }^{30}$ mostrar las armas a los estudiantes y mostramos el "Horacio" que era un arma del Lautaro, un arma hechiza... y resultó un fiasco la demostración porque no funcionó. Justo ese día no... bueno, era por demostrar que nosotros podíamos fabricar nuestras propias armas. Aunque no funcionaran (risas). ${ }^{31}$

Coincidente con la entrada de la transición, el alza de acciones armadas del Lautaro de mayor envergadura significó una mayor atención tanto en lo mediático y en la opinión pública, como también en los propios cánones institucionales y los aparatos coercitivos del Estado. Con la aparente libertad que llegaba de la mano con la democracia, el destape cultural que vendría tras los diecisiete años de límites impuestos por la dictadura, auguraba trabajo sobre tópicos de género e incluso a nivel cultural se comenzó a apreciar en mayor medida la diversidad sexual, aunque por cierto no aceptada y desenvuelta en un espacio underground. Por contraparte, el segmento más conservador de la sociedad defendía esta vez la moral bajo los conceptos de paz social y seguridad ciudadana, propugnados por el gobierno de la transición y amparados en el marco legislativo democrático. La flamante democracia y la nueva década traían la mayor persecución que terminaría con la guerra del Lautaro.

\section{Solidaridad y resistencia tras las rejas}

Tras el triunfo del No en 1988, la democracia pactada comenzó a regir el país desde 1990 hasta nuestros días. Así también comenzó la batalla del gobierno del democratacristiano Patricio Aylwin, contra los grupos que se posicionaron contra la farsa electoral y la legitimación del modelo impuesto en dictadura, como el Frente Autónomo (FPMR-A), el MIR-EGP ${ }^{32}$ y el Lautaro, indicados como desadaptados que no

29 Zalaquett, Chilenas en armas, 281.

30 Denominación dada al ex Instituto Pedagógico de la Universidad de Chile, hoy Universidad Metropolitana de Ciencias de la Educación.

31 Entrevista personal, Claudia, octubre 13, 2017.

32 "Ejército Guerrillero de los Pobres". Más tarde se añadiría "Patria Libre" (MIR EGP-PL). 
tendrían espacio en el Chile demócrata. Bajo el concepto de la seguridad ciudadana, el gobierno de la transición dispuso mecanismos de control y represión para desbaratar dichas organizaciones, entre los que figuraron el Consejo Coordinador de Seguridad Pública o "La Oficina", su sucesora, la Dirección de Seguridad Pública e Informaciones (DISPI) y, por cierto, las fuerzas de orden y seguridad: Carabineros y Policía de Investigaciones (PDI). Uno de los primeros golpes represivos considerables que atacó al Lautaro sucedió en octubre de 1989, con detenciones múltiples en Santiago, Valparaíso y Coquimbo, las cuales terminaron con decenas de militantes presos, conocidos como el "grupo de octubre", donde figuraban nuestras entrevistadas. El incremento de fuerzas y atribuciones que poseían los entes represivos tras el Lautaro, permitió la caza de militantes en una constante que no se detuvo hasta la detención del propio Secretario General en 1994. Pero incluso antes de la arremetida concertacionista, la policía había adquirido un potencial considerable para la desarticulación de las organizaciones guerrilleras y subversivas. Los trabajos de inteligencia sobre el Lautaro comenzaron a dar frutos a fines de la década de 1980, coincidiendo los últimos días del régimen con el alza de acciones armadas. Una entrevistada señala:

Era un factor sorprendente que nosotras tuviéramos roles de mayor responsabilidad o acción... a los $\operatorname{pacos}^{33}$ les sorprendía, yo me acuerdo cuando me detuvieron, ellos pensaban que una estaba ahí pa' acostarse con los demás y te lo decían. ${ }^{34}$

El golpe al grupo de octubre, tras un CTA en pleno centro de Santiago y que terminó con la muerte de un efectivo de carabineros, es recordado por los ex militantes del Lautaro como una de las primeras acciones represivas más significativas para la organización, comenzando la vida en la cárcel donde tuvo lugar la discusión, la autocrítica, los cuestionamientos, así como también la organización y la resistencia, ahora desde otro "bastión". Observar la experiencia de ser mujer en el espacio carcelario, aparece como un punto de inflexión necesario y obligatorio en la historia del Lautaro si consideramos que este espacio fue un implícito detonante de distintas percepciones que actualmente se pueden asociar al feminismo. Aunque despojadas de teorizaciones académicas y conceptualizaciones específicas, las distintas prácticas al interior de la cárcel, -como un espacio que taxativamente divide entre sexos de manera binaria y que por si fuera poco, supone la presencia de una ruda jerarquía enemiga al servicio del sistema penitenciario- fueron en muchas ocasiones acercamientos primigenios a la solidaridad de género (lo que hoy en día conocemos como sororidad) y finalmente, sostuvieron la resistencia al diario vivir tras las rejas. Por otra parte, la autocrítica devenida al interior de la cárcel de mujeres dio paso a distintos caminos; por diversos motivos, varias de ellas terminaron su militancia con el Lautaro (para nuestro caso de

33 Denominación popular para Carabineros.

34 Entrevista personal, Mujer ex lautarista, diciembre 9, 2016. 
estudio) y desde aquí optaron por una lucha asociada a los derechos humanos e incluso, tuvieron un acercamiento mayor al anarquismo u otras corrientes libertarias. En este sentido, en más de una ocasión, la prisión "significó tener el tiempo para analizar su militancia, su relación de pareja, y sus decisiones familiares y hubo una cantidad no menor de mujeres que empezaban a aplicarles a estos análisis una mirada feminista" ${ }^{" 35}$. Como ejemplo, Claudia recuerda muchas discusiones con mujeres militantes del MIR en torno a lo político, pero aun así la fraternidad entre ellas se tomaba su lugar de manera fluida. Rescatamos en este apartado final aquellas vivencias propias de las lautarinas que, significativamente marcaron un antes y después para nuestras entrevistadas tras la experiencia carcelaria; nos preguntamos cómo fue esta experiencia y de qué manera influyó en la militancia lautarina, tanto en lo orgánico como en sus militantes.

\section{1 "Aquí la lucha sigue": Lautarinas y Guacoldas}

La cárcel significó un vuelco en la actividad política, en tanto parte importante de la militancia se vio encarcelada por extensos periodos y la división entre mujeres y hombres, propia del sistema carcelario, alejó a los principales dirigentes -hombres, por cierto- de las lautarinas, dando paso a pugnas internas en el espacio penitenciario masculino, en relación más directa con los jefes de la organización, así como también el término de la militancia de algunas lautarinas. Claudia indica que, en "la cárcel de la democracia hubo hartas chiquillas del Lautaro y fueron bien confrontacionales con el partido, rebeladas con la dirección, no acataban siempre lo que les decían". ${ }^{36}$ Una vez al interior de la cárcel, la militancia requirió cambiar de perspectiva: el accionar político adquirió el tinte de resistencia y un tanto de dignidad ante el régimen carcelario al que se vieron enfrentadas. Una entrevistada señala:

Cuando yo caí había harta efervescencia en torno a la cárcel, éramos un colectivo de presas políticas y elaborábamos un actuar conjunto, más allá de tu militancia (...) nos movilizábamos al interior, hacíamos tomas, huelgas de hambre... por lo menos en los años que estuve presa, siempre fue así y en general, más allá de las diferencias políticas -que sí las habían- se podía trabajar juntas. ${ }^{37}$

El encarcelamiento de las jóvenes lautarinas se vio cargado de distintas acciones organizadas por las presas bajo el ideario de mantener la lucha y también sobrellevar los días en el penal. Una entrevistada recuerda: "mi mamá tenía las tarjetas que hacíamos pal 8 de marzo, con la mona pilucha y la metralleta y después yo la miré y decía

$35 \quad$ Hillary Hiner, “Fue bonita la solidaridad entre mujeres’: género, resistencia, y prisión política en Chile durante la dictadura," Estudos Feministas 23, no. 3 (2015): 879.

36 Entrevista personal, Claudia, octubre 13, 2017.

37 Entrevista personal, Mujer ex lautarista, diciembre 9, 2016. 
'qué tiene que ver...' pero ese era el espíritu, la rebeldía (risas)". ${ }^{38}$ Sobre las actividades propias del día a día en la cárcel, Claudia reflexiona en retrospectiva y comenta:

El tiempo que estuve, dónde estuve y esas condiciones hicieron que viviera una "buena" cárcel, no traumática. Entre mujeres igual se ve una solidaridad especial, que ahora llaman sororidad y de hecho, con mucha gente que conocí ahí hasta el día de hoy tengo relaciones de amistad. ${ }^{39}$

¿Cómo se observaban las prácticas de sororidad? Distintos momentos daban paso a pequeñas y grandes muestras de solidaridad de género, organización, apoyo mutuo y ánimo hasta en las actividades más recreativas. Sobre las artesanías que realizaban en la cárcel, Claudia recuerda: "era una obligación, pero no todas éramos dotadas en las artes manuales. Había una Mirista que me enseñaba a tejer monitas de lana y yo... no era muy dotada. Pero ella me decía 'jbravo, tú puedes!' ${ }^{40}$. Por otro lado, nuestra entrevistada anónima relata una de las luchas más organizadas, en la cual sintió gran apoyo entre las presas políticas con que cohabitaba aquellos espacios:

Al principio nosotras no teníamos derecho a venusterio, entonces como éramos patudas, las que teníamos pololo armamos un lugar en un taller que teníamos, donde recibíamos la visita y ahí armamos nuestro rincón del amor. Un día estábamos en la visita y... yo estaba con mi pololo y llegó el jefe de la unidad, se metió hasta donde yo estaba y nos castigaron sin visita. Entonces hicimos todas una toma, para que se restituyeran. Todas jugadas. Nos dieron las visitas de nuevo y después teníamos visitas en las celdas... siempre nos organizamos y tuvimos harto apoyo. ${ }^{41}$

Hiner señala que "las mujeres presas lograron activar redes, a veces precarias por la naturaleza de su ambiente, de solidaridad y autocuidado dentro de estos espacios"42. Efectivamente, las redes formadas en la cárcel permitieron que cada agrupación coordinara su propio espacio para el trabajo en conjunto por la libertad de presas y presos políticos. Lo interesante, es que logró salir de los muros carcelarios y tener presencia en las calles de la democracia. Así nació el "Movimiento Madres Guacolda", que se configuró hacia el año $1989^{43}$, lo que coincide con el apresamiento del grupo de octubre, tal como lo recuerda Claudia también, quien señala: "no sé si cuando nosotros caímos se formaron las Guacolda o poquito antes... porque antes habían como dos

$38 \quad$ Entrevista personal, Mujer ex lautarista, septiembre 20, 2017.

39 Entrevista personal, Claudia, octubre 13, 2017.

40 Entrevista personal, Claudia, octubre 13, 2017.

41 Entrevista personal, mujer ex lautarina, septiembre 20, 2017.

42 Hiner, "Fue bonita la solidaridad entre mujeres...," 882

43 Valentina López y Javiera Poblete, "Movimiento Madres Guacolda: Un acto de subjetividad política, (1989-1994)". (Tesis de licenciatura, Universidad ARCIS, 2008), 113. 
presos del Lautaro, dos o tres presos, entonces ellos se acoplaban a otras orgánicas" ${ }^{\prime 4}$. Sin embargo, con el alza considerable de presas y presos lautaristas, surgió la necesidad de tener un colectivo en referencia hacia el exterior, y así las Guacolda empezaron "a tomar forma a medida que van cayendo presos los miembros del 'Movimiento Lautaro', en el cual participaban los hijos e hijas, parejas, hermanos y hermanas, de estas mujeres que comienzan a organizarse y a conformarse como 'Movimiento Madres Guacolda" "45. La organización del movimiento las llevó a realizar acciones para conseguir la libertad o para conseguir algunos beneficios como señaló antes una de nuestras entrevistadas, tales como obtener más días de visita, acceder a visitas con parejas o la mejora de ciertas condiciones penitenciarias.

Las principales manifestaciones y acciones como movimiento se realizaron desde 1990, cuando se encadenan en los tribunales de justicia, hasta el imperioso traslado a la Cárcel de Alta Seguridad, en donde la lucha se agudiza por parte de los familiares, ya que ven que no hay posibilidades de movilización, y no hay respuesta por parte de autoridades y políticos. ${ }^{46}$ Una vez fuera de la cárcel, en las condenas más breves, la opción para enfrentarse a las arremetidas del gobierno demócrata se plasmó en las Guacolda, siendo este el camino en el que Claudia pudo continuar en apoyo a quienes aún se encontraban tras las rejas, incluso habiendo terminado su militancia en el Lautaro, como pasó en más de un caso. Al respecto, anotaba lo siguiente:

¡Fue una experiencia muy difícil!, porque eran señoras no politizadas... súper lindas todas las mamás, pero lograr que entendieran políticamente porqué sus hijos estaban presos y habían tomado las armas y militaban, muy pocas entendían. Las señoras iban por amor, igual les decías "¡Hay que estar tal día a tal hora en tribunales y nos vamos a encadenar!" y ahí estaban ellas, súper dispuestas. ${ }^{47}$

Similar a los movimientos pro derechos humanos surgidos durante la década de 1980, las mujeres adquirieron un lugar importante en la denuncia por los remanentes de la prisión política en los gobiernos demócratas en Chile. El Movimiento Madres Guacolda se extendió hasta aproximadamente el 2004, en la misma tónica de resistencia, solidaridad y lucha hasta que comenzaran a salir de las cárceles la mayor parte de los presos políticos del Lautaro y otras orgánicas. Tras encarcelamientos, extrañamientos y muertes, Lautaro dejaba tras de sí un importante legado en cada uno de sus militantes que hasta el día de hoy permea de diversas maneras las vidas de quienes decidieron ir más allá y apostar por un cambio revolucionario en Chile.

$44 \quad$ Entrevista personal, Claudia, octubre 13, 2017.

45 López y Poblete, Movimiento Madres Guacolda, 114.

46 López y Poblete, Movimiento Madres Guacolda, 115.

47 Entrevista personal, Claudia, octubre 13, 2017. 


\subsection{Recomenzar}

La experiencia carcelaria dejó ver distintos lazos y expresiones de solidaridad y resistencia al sistema carcelario entre distintas orgánicas, desde donde provenían muchas presas. Renunciando a la militancia en el Lautaro, cumpliendo condenas, saliendo de la cárcel, nuestras entrevistadas se volcaron a otros desafíos, despojadas de la organización que las cobijó y enfrentando las complejidades del contexto de la época. Y aunque las acciones del Lautaro quedaron como recuerdo de nuestras entrevistadas y de tantas otras, aún ellas rescatan la casi herencia en que se transformó su militancia en el MJL. Una ex lautarina indica de manera tajante y certera: "a mí la izquierda me arrojó al feminismo, yo soy feminista ahora"48; así mismo, anota:

Yo siempre creí que Lautaro tenía razón y efectivamente no iba a cambiar nada... y con los años digo "iqué visionarios fuimos!" (risas) siempre estuve en esa lógica, que al final era más antisistémica que antidictadura... en eso me siento bien lejana de un montón de posturas de la izquierda hoy... a mí me influenció mucho haber sido del Lautaro, no lo niego. Es parte de mi estructura, de mi manera de pensar, de cosas que me definieron... yo me siento todavía -aunque sea una señora- profundamente antisistémica. Quizás en esa época no hablábamos así, pero creo que es mucho la tónica que siguió. ${ }^{49}$

Julieta Kirkwood afirma, a manera de sentencia, que "La incorporación de las mujeres al mundo será para el movimiento feminista un proceso transformador del mundo. Se trata, entonces, de un mundo que está por hacerse y que no se construye sin destruir el antiguo" ${ }^{50}$. En este sentido, no sería casual que podamos encontrar estas reflexiones en ex militantes del MAPU-Lautaro. La implicancia histórica que adquirió la organización en tanto fue una de las pocas que abarcó temáticas que iban más allá de lo inmediato y urgente, si bien de manera somera o incluso desconociendo los significados de las prácticas políticas cotidianas de jóvenes lautaristas, puede ser uno de los explicativos principales al acercamiento realizado por ex militantes de la resistencia armada en Chile, a distintas corrientes teóricas que han ido variando los análisis sociológicos o historiográficos. De esta manera, no parece extraño ni lejano que la aparente categoría de "visionarios" que señala nuestra entrevistada, por más jocoso que pueda parecer, estaría aplicando de manera muy cercana al Chile de hoy, cuando apenas en 2018 se está abriendo a temas de género y con gran reticencia desde los sectores más duros del conservadurismo.

A través del recorrido que hemos realizado, podemos ver que la trayectoria militante se establece como parte de la identidad de cada una. Poder posicionarse hoy en

$48 \quad$ Entrevista personal, mujer ex lautarista, diciembre 9, 2016.

49 Entrevista personal, mujer ex lautarista, septiembre 20, 2017.

50 Kirkwood, Ser politica en Chile, 65. Las cursivas son del original. 
día desde algún "bastión" en lucha contra el sistema imperante, tal como se dispusiera en algún momento en las filas del Lautaro, recoge el legado de un pasado de lucha que parece hoy tener más sentido que nunca y que, por cierto, hoy permite a las mismas protagonistas de ayer, tomar sentido a la relevancia histórica que adquirió su presencia en aquel momento y lugar.

\section{Conclusiones}

Rescatar la experiencia militante desde la mujer en el Lautaro, nos posiciona frente a ciertos escenarios que hemos relevado en los tres apartados del trabajo: los orígenes de la politización de las jóvenes lautarinas, las relaciones sociales establecidas entre militantes comprendidas desde una perspectiva de género, y poder entender la cárcel femenina como un espacio doblemente punitivo, evidenciando la sanción moral y fáctica, en tanto la moral insiste en encasillar a la mujer en su rol sumiso y hogareño. Podemos señalar que, en torno a la actividad política de la mujer lautarina, no parece casual que hayan optado por un camino de lucha concreta en el afán de "hacer algo" que se comenzó a evidenciar desde las militancias en otras organizaciones, cuyos inicios a su vez, también evidencian relación con el contexto social de la época. Por otra parte, dentro de las filas del Lautaro, se podría observar una eventual complejización, en tanto los roles de género dieron paso a una u otra actitud que incluso podría decir más de la propia organización que tan solo de las relaciones interpersonales. En este sentido, creemos absolutamente necesario, -aunque pudiera parecer a primera vista un tanto simplista- contextualizarnos en el momento vivido y todos los factores a su alrededor; nuestras entrevistadas coincidieron en señalar que en la sociedad no existían preocupaciones tales como hoy se posicionan en la palestra de las movilizaciones y demandas sociales. Nos preguntamos al inicio del presente trabajo si no fue característica del Lautaro incorporar a sus políticas reivindicaciones relegadas por la izquierda tradicional, pero bien comprendemos la inserción en la sociedad y la necesidad de sacar al dictador y sus legados como factores de casi ensimismamiento que no permitieron dar el salto más allá, al menos en lo pragmático; la práctica diría hoy otra cosa.

Creemos que la experiencia carcelaria es una síntesis aplicable al proceso de nuestras entrevistadas y que si bien, evidentemente no será el absoluto de cada una de las otrora lautarinas, es clara tendencia de politización y resistencia. Señalamos un doble espacio de castigo para la prisión femenina, inmersa en una sociedad machista que penaliza y criminaliza la lucha social tanto desde la propia moral ciudadana como desde el rol de género tomado frente a la sociedad. El caso de Marcela Rodríguez, que dejó al descubierto una de las principales mujeres metralletas y que empapó a la opinión pública de estereotipados comentarios cargados también del discurso oficialista se convirtió entonces en la sanción moral a la que nuestras entrevistadas hacen alusión. Por otro lado, los encarcelamientos, muy por el contrario a lo esperado por el 
sistema penitenciario, reforzaron de muchas maneras el carácter de rebeldía que cada lautarina forjara y plasmara en su identidad. Aun cuando la militancia terminara, los lazos de solidaridad dentro del sistema legitimado por la democracia permanecieron ahí y hasta hoy en día es posible observar en algunas lautarinas, cómo la herencia del Lautaro se mantiene intacta, incluso cambiando los espacios de luchas, canalizando las ganas de cambiar la sociedad. Según Zalaquett, una de los actos de mayor subversión de una ex lautarina habría sido parir esposada ${ }^{51}$, en una de las tantas expresiones de resistencia al sistema carcelario, pero tal ejemplo no parece tan lejano ni propio de la compleja transición a la democracia. En octubre de 2016, Gendarmería de Chile obligaba a la comunera mapuche Lorenza Cayuhan, a dar a luz engrillada y en presencia de personal masculino de Gendarmería, en pleno segundo mandato de Michelle Bachelet. ${ }^{52}$ Tal parece que las tímidas políticas públicas sobre género no aplican para todos los sectores, ni conllevarían los requerimientos del feminismo per se. Sumar las categorías de clase y raza al estudio de género parece ser un importante punto aún invisibilizado.

Por otro lado, creemos necesario destacar un hecho que ha sido vagamente estudiado y que tendría conexión con las relaciones intracarcelarias entre presas políticas y presas "comunes"; se trata del hecho de que en ocasiones no ha surgido de manera automática la sororidad y apoyo mutuo entre las prisioneras, pudiendo llegar incluso a hacer alianzas con las propias carceleras aquellas tal vez mal llamadas presas comunes. ¿Clase o género? Creemos que este es un debate interesante y necesario de observar, para lo cual podemos dar pie a futuras investigaciones.

El rol activo de la mujer en la lucha armada, más allá de los cánones burocráticos a los que se acuñaran las primeras feministas burguesas, sigue siendo un tema en mora frente a la desbordada producción académica sobre la casi historia del hombre. Disputar espacios es también una lucha desde otra perspectiva. La práctica y el ejercicio de memoria activa recoge el legado de quienes ya no están, e inserta en la actualidad aquellas necesarias batallas que surgen día a día y que complejizan e inscriben nuevos desafíos en los procesos de la historia reciente.

$51 \quad$ Zalaquett, Chilenas en armas, 313.

52 Leonardo Casas, "Denuncian que gendarmes mantuvieron a comunera mapuche engrillada durante parto en Concepción," BioBioChile, octubre 17, 2016. https:/www.biobiochile.cl/noticias/nacional/region-delbio-bio/2016/10/17/denuncian-que-gendarmes-mantuvieron-a-comunera-mapuche-engrillada-durante-partoen-concepcion.shtml 


\section{Bibliografía}

\section{Fuentes primarias}

\section{Impresos.}

"La Toma de lo cotidiano: entrevista a Diego Carvajal, secretario general del Partido MAPU.", facsímil, febrero 1990.-

\section{Entrevistas}

Mujer, ex lautarista (anónimo a petición de la entrevistada):

Entrevista personal, 9 de diciembre de 2016.

Entrevista personal, 20 de septiembre de 2017.

Claudia, ex lautarista:

Entrevista personal, 7 de diciembre de 2016.

Entrevista personal, 13 de octubre de 2017.

Andrea, ex lautarista:

Entrevista personal, 30 de noviembre de 2016.

Marco, ex lautarista:

Entrevista personal, 18 de enero de 2016.

\section{Fuentes secundarias}

Bonino, Luis. “Los Micromachismos". Revista La Cibeles. (2004).

Casas, Leonardo. "Denuncian que gendarmes mantuvieron a comunera mapuche engrillada durante parto en Concepción," BioBioChile, octubre 17, 2016. https:// www.biobiochile.cl/noticias/nacional/region-del-bio-bio/2016/10/17/denuncian-que-gendarmes-mantuvieron-a-comunera-mapuche-engrillada-durante-parto-en-concepcion.shtml

Dietrich, Luisa. "La 'compañera política': mujeres militantes y espacios de 'agencia' en insurgencias latinoamericanas." Colombia Internacional 80.1 (2014): 83133.

Fauré, Eyleen. Los locos del poder. Aproximación histórica a la experiencia del Mo- 
vimiento Juvenil Lautaro. (1982-1997). Santiago: Universidad de Chile, 2006.

Garcés, Mario y De la Maza, Gonzalo. La explosión de las mayorías. Protesta nacional 1983-1984. Santiago de Chile: Editorial ECO, 1985.

Goicovic, Igor. "Temas y debates en la historia de la violencia política en Chile." Contenciosa 3, no. 2 (2014): 1-16.

Hiner, Hillary. “'Fue bonita la solidaridad entre mujeres': género, resistencia, y prisión política en Chile durante la dictadura." Estudios Feministas 23, no. 3 (2015): 867-892.

Kirkwood, Julieta. Ser politica en Chile. Las feministas y los partidos. Santiago de Chile: FLACSO, 1986.

López, Valentina y Poblete, Javiera. Movimiento Madres Guacolda: Un acto de subjetividad politica, (1989-1994). Santiago: Universidad ARCIS, 2008.

Scott, Joan. "El género: una categoría útil para el análisis histórico." En Historia y género: las mujeres en la Europa moderna y contemporánea, editado por Mary Nash y James Amelang, 23-56. Valencia, España: Editorial Alfons el Magnánim, 1990.

Necoechea, Gerardo. "El proceso de politización desde una perspectiva de historia oral: militantes de izquierda latinoamericanos, 1960-1990." Revista Tempos Históricos 17 (2013): 162-182.

Zalaquett, Cherie. Chilenas en armas: testimonios e historia de mujeres militares y guerrilleras subversivas. Santiago de Chile: Ed. Catalonia, 2009. 